\section{Surrogate cells}

\section{A. D. Bangham}

Journal of Liposome Research. Editor Leaf Huang. Dekker. 3/yr. \$225 (institutional); $\$ 112.50$ (personal).

SMECTIC mesophases (layer lattices of amphiphilic molecules in water, alias 'myelins' and now called 'liposomes') would have been found on our planet long before covalently linked nucleic or amino acids; in other words, membranes came first. Some 30 years ago, I and my colleagues recognized the fact that such structures, made with phospholipids of biological origin, spontaneously formed systems of closed membranes when placed

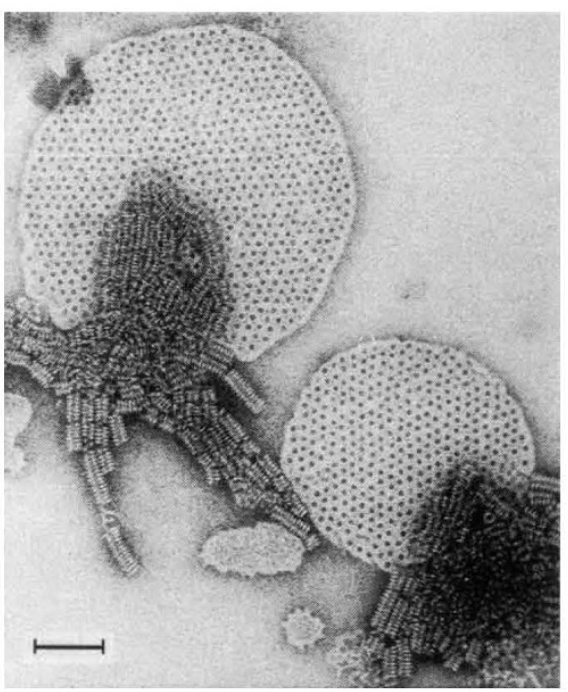

Cholesterol-containing multilamellar liposomes challenged with a dilute solution of saponin and negatively stained with sodium phosphotungstate. From A. D. Bangham, Advances in Lipid Research 1, 65-104 (1963). Scale bar, 1,000 A.

in water - that is, surrogate cells.

Early papers describing their structure and properties were despatched, of necessity, to molecular, biochemical and biophysical journals for peer review and acceptance depending on their particular slant. Biological membranes were in vogue in the $1960 \mathrm{~s}$ and the attributes of their bimolecular simplicity marvelled at; the (passive) properties of all biological cell membranes were revealed! But the main impetus for additional research arose from the idea that liposomes might be used as nontoxic, biodegradable, addressable envelopes to deliver potent drugs precisely and quickly or, alternatively, surreptitiously and slowly.

My liposome database (LIFO Avestin Inc., Ottawa) now contains about 14,000 references going back to 1965 , with additions running at roughly 1,000 a year. This new journal should have no difficulty in selecting "high quality articles in the area of liposome research", the avowed aim of the editor and his board.

Volume 2 is now in the, perhaps, neutral hands of an editor based within a university department. There is also a generous representation on the editorial board of scientists working in both commercial and academic fields.

I approve of the "Forum" section, in which a panel of interested workers in a particular fieid is invited to comment on a group of published papers. The comments amplify the salient points made in the seminal articles under scrutiny and, in the long run, will help to defuse controversial issues.

With the choice of camera-ready text, publication time should and would seem to be acceptable, although one wonders, in view of the ease with which one can alter text with wordprocessors, why there is such a great variation in font style. It does, however, add flavour.

A. D. Bangham is at 17 High Green, Great Shelford, Cambridge CB2 5EG, UK

\section{Cellular therapies}

\section{Kathryn Wood}

Cell Transplantation. Editor-in-chief Paul R. Sanberg. Pergamon. 6/yr. £210, \$325 (institutional); $£ 57, \$ 88$ (personal).

TRANSPLANTATION is a growing discipline. If the launch rate for new journals covering different aspects of the field is a reflection of the rate of progress in the development of strategies that will ultimately find application in clinical practice, then exciting times are ahead.

The transplantation of cells rather than whole organs is by no means a new idea. But whereas the transplantation of solid organs is now accepted as a useful therapeutic strategy, transplantation of bone marrow is the only clinical discipline in which single cells are transplanted on a regular basis. The current lack of routine clinical application of cell transplantation does not reflect a lack of interest in the potential of this approach; hence the advent of Cell Transplantation, which aims to provide a forum for discussion of transplant research at the cellular level.

There are many disease states in which cell transplantation might eventually be used as a form of treatment, including diabetes, certain forms of hepatic insufficiency, some neurological disorders and muscular dystrophy, to name but four. And an even more exciting future therapeutic prospect is the transplantation of genetically modified cells. In the first few issues, the journal has published original experimental and clinical studies in each of these areas and others, including reports of advances in the technology for growing isolated cells in vitro and their encapsulation in artificial membranes. The quality of the papers is improving. But in attempting to cover not only all the potential clinical applications but also the developments in the many technologies that will be required for the successful clinical application of cell transplantation, the scope of the journal may be too broad to provide comprehensive coverage.

The editorial board consists of distinguished workers and is subdivided into areas of expertise. An editor with specialist knowledge has been designated for each section, a policy that ought to ensure the quality of the papers. So far, the content has varied from issues containing only original papers to issues exclusively consisting of invited reviews. Because of the potential clinical application of the research, the editor has chosen to include a section of abstracts from recently issued US patents. In some issues there is also an editorial section for the discussion of controversial issues, such as the use in the United States of fetal tissue for clinical transplantation research. The editors should now cater for wider international interests by broadening the focus to other areas of the world.

The advent of this journal was well timed. With good editorial guidance, Cell Transplantation should develop to become the leading publication in this specialized area.

Kathryn Wood is in the Nuffield Department of Surgery, University of Oxford, John Radcliffe Hospital, Oxford OX3 9DU. UK.

\section{Sensible medicine?}

\section{lan Gibson}

Antisense Research and Development. Editors James Hawkins, Arthur M. Krieg and $\mathrm{Cy}$. A. Stein. Liebert. 4/yr. USA and Canada, \$121; elsewhere $£ 161$.

IF there are still doubters who believe 'antisense' is too clever by half or that it just does not work, then they should take a look at a review in a recent issue of this journal of a US meeting on the subject:

The conference ended on a very enthusiastic notc about the future of nucleic acid-based therapeutics in medicine. Based on the data presented at the conference, it became clear that many of the major objections that some scientists had raised in the past about antisense and the other technologies are rapidly becoming moot. Oligonucleotides can be quite stable 